\title{
A MÚSICA E A DITADURA MILITAR: COMO TRABALHAR COM LETRAS DE MÚSICA ENQUANTO DOCUMENTO HISTÓRICO
}

\author{
MUSIC AND A DICTATORSHIP MILITARY: \\ WORKING WITH LETTERS OF MUSIC HISTORY AS DOCUMENT
}

\author{
Bruno Paviani \\ Thaisa Lopes Ferreira ${ }^{1}$
}

\begin{abstract}
RESUMO: Na turma do $9^{\circ}$ ano $B$, trabalhamos com a música enquanto fonte histórica. As músicas escolhidas foram dos compositores Raul Seixas e Zé Ramalho e a banda Legião Urbana. A partir da temática "Ditadura Militar", a aula-oficina (BARCA, 2004) teve como prioridade trabalhar com as ideias históricas já apresentadas pelos próprios alunos. Para tanto aplicamos um questionário de conhecimentos prévios, uma vez que entendemos que nossos alunos já possuem um determinado conhecimento sobre o tema. Com esse material em mãos, preparamos nossa intervenção em sala de aula. Ao estudarmos a música enquanto fonte histórica, percebemos que essa não serve apenas para diversão direta ou indiretamente, as músicas retratam muito sobre a sociedade em que é produzida e são também instrumentos de crítica. Após essa intervenção, consideramos fundamental o uso de documentos durante as aulas de História. O documento torna a aula mais interativa e aproxima os alunos do trabalho do historiador.
\end{abstract}

Palavras-chave: Educação histórica. Música. Ditadura militar. Fonte histórica.

ABSTRACT: In 9th grade $B$, we worked with the music while historical source. The songs, that we used, were made by Raul Seixas and Zé Ramalho and the band Legião Urbana. Beginning from the thematic "Dictatorship military", the lecture-workshop (BARCA, 2004) had - like priority - to work with ideas related with History- that had already introduced by the students. We made a quiz with foreknowledge, once we understand that our students have knowledge about the theme. With this material in hands, we prepared our intervention at the classroom. When we study the music while historical source, we perceive it isn't use only to fun (direct or indirectly ways), the songs show much about the society where they are produced and they are critical instruments. After the intervention, we consider the use of documents during the History's class fundamental. The document makes the class more interactive and can create bows with the students and the historian's work.

Keywords: Historical education. Music. Dictatorship military. Historical source

1 Graduandos em História pela Universidade Estadual de Londrina e Bolsistas PIBID/CAPES. 


\section{Introdução}

Sobre o ensino de História, é preciso pensar em que conteúdos devem ser ensinados, o que será priorizado, de que maneira serão ensinados e com que finalidade. Ao definir isso, define-se o papel do professor em sala de aula e o papel que o ensino terá para os educandos. Os próprios questionamentos sobre o que ensinar e a maneira como isso será feito, remetem sempre a perguntas como o porquê ensinar História e sua importância para a formação do aluno. O ensino de História está relacionado à formação do cidadão e da construção de sua identidade. E por esta razão, tem se uma preocupação ao que será ensinado. É preciso entender a educação enquanto uma forma de intervenção no mundo. O que professor deve ter em mente é que seu curso não é transformador do mundo, mas o que acontece na escola é um momento em que se começa essa transformação.

Em contrapartida, além de se pensar o papel do ensino, é preciso entender o papel do docente nesse processo. Para Paulo Freire (2004) em "Ensinar é um especificidade humana" a principal característica que um docente tem que ter é segurança quanto a sua atuação, sem que haja de maneira autoritária. O professor não deve contar com os conhecimentos prévios de seus alunos. É preciso dar liberdade ao aluno para que pense por si próprio, que construa seu conhecimento a partir de suas próprias ideias. O professor deve cuidar de suas atitudes dentro de sala de aula, uma vez que isso pode ajudar ou atrapalhar seu trabalho. Suas atitudes podem aproximar ou afastar o aluno. Por outro lado, o professor também deve estar atento de que maneira seus alunos o interpretam. As releituras que os próprios alunos fazem das atitudes do educador.

(...) se o professor estiver empenhado em participar numa educação para o desenvolvimento, terá de assumir-se como investigador social: aprender a interpretar o mundo conceitual dos seus alunos, não para de imediato o classificar em certo/errado completo/incompleto, mas para que esta sua compreensão o ajude a modificar positivamente a conceitualização dos alunos, tal como o construtivismo social propõe. Neste modelo, o aluno é efetivamente visto como um 
dos agentes do seu próprio conhecimento, as atividades das aulas, diversificadas e intelectualmente desafiadoras, são realizadas por estes e os produtos daí resultantes são integrados na avaliação (BARCA, 2004, p. 133).

Ensinar conteúdos é apenas um dos momentos da prática pedagógica. As ações do professor devem condizer com o que este fala em sala de aula. O professor deve cuidar para que sua autoridade não ultrapasse limites, que ele próprio não se perca em sua autoridade.

Ao ouvir o aluno, o professor estabelece respeito a concepção de mundo do educando e facilita até o seu próprio trabalho. Para Paulo Freire (2004), priorizar as relações humanas é fundamental para o trabalho em sala de aula. Com todas essas cobranças, o professor ainda deve cuidar para que sua fala em sala de aula não soe aos alunos como uma doutrinação. É preciso sempre ter em mente que o professor não está em sala de aula com a função de ser o detentor supremo do conhecimento, que não deve agir como só suas ideias fossem válidas naquele espaço.

Maria Laura P. Barbosa Franco e Gláucia Torres Franco Novaes (2001) farão um panorama de como se desenvolve as representações acerca da escola em "Os jovens do Ensino Médio e suas representações sociais". Para tanto, as autoras partem de como está organizado o ensino, a formação dos professores. Uma deficiência a maneira como Novaes e Franco estruturam sua pesquisa, faz-se pensar no que deve ser levado em conta ao se estender não só o ensino de História, mas o papel que a educação deve exercer em uma sociedade. Embora as autoras partam do ensino médio, o trabalho também pode ser utilizado para outros níveis de ensino.

As condições de trabalho dos professores também não são das mais fáceis. O professor tem que lidar com as más condições do espaço físico da escola, a falta de recursos e seu baixo salário. As autoras propõem que ao menos durante seu horário de trabalho, o professor tenha tempo para planejamento das aulas, interação com os alunos. Hoje em dia, as escolas já estão mais bem equipadas e o professor já tem um tempo destinado em sua carga horária para a preparação de aula. Mas isso ainda acontece de forma tímida, uma vez que a "hora atividade" ainda é pouca comparada a carga horária que o professor tem que cumprir. 
Para os alunos, a educação, a escola, está ligada a ascensão social, a uma vida melhor, a melhores salários. Esse tipo de pensamento vem dos próprios pais e é muito perceptível principalmente nos alunos que já trabalham. A escola é uma promotora de crescimento econômico e social para esses alunos. Diante de todas essas perspectivas, fica claro que uma das funções da escola ao final do ciclo escolar é preparar o aluno para o mercado de trabalho. E essa ideia acompanha os alunos desde seu primeiro momento escolar. A dinâmica escolar, muitas vezes, se compara a dinâmica do mercado financeiro. Infelizmente, enquanto a escola não assumir seu real papel, que é formação de jovens conscientes, capazes de refletir sobre a sociedade a qual estão inseridos. A escola deve encarar seus problemas, afim de que crie propostas coerentes com a sua realidade.

O ensino ainda se mantém muito mecânico, apenas voltado para a memorização. As inquietações por parte dos alunos têm seu sentido, uma vez que as aulas são mais voltadas a decorar o conteúdo, proposto pelo livro didático. Não há uma apropriação do que eles já sabem de sua realidade, de seus conhecimentos para a aula, o professor deve considerar é que a criança é capaz de formular seus próprios conceitos, são capazes de entendê-los.

Mais uma vez, para isso, o professor deve ter total compreensão da disciplina que está lecionando, de seus pressupostos metodológicos, teóricos e no caso da História, historiográficos. Para tanto, é preciso cuidar para a formação do professor, para que esta não seja tão rasa a ponto de não dar suporte ao profissional.

São muitas as questões que permeiam o pensamento sobre a educação, e todas devem ser consideradas. Não se deve pensar a educação individualmente. A educação não deve ser fechada, mas se expandir para todas as discussões que possam ser realizadas a seu respeito. Tanto seu papel, quanto o papel do professor e do aluno devem sempre ser revistos, uma vez que isso vai se modificando com o tempo. Novas realidades criam novas necessidades e a escola, o professor e seus alunos devem estar preparados para essas possibilidades. Não somente a isso, mas se a educação deve exercer mesmo o seu papel de formadora de cidadãos 
conscientes, capazes de refletir a cerca de sua realidade, alunos transformadores, ela não pode ficar relegada a dominação de pensamento de determinadas camadas da sociedade, não se pode deixar levar pela doutrinação, função essa do professor, que deve estar consciente de que seu papel é de mediador do conhecimento e não "dono do conhecimento". É deixar que o aluno por si só perceba que é capaz de entender conceitos, pelo menos a começar entender o mundo a partir se sua própria realidade.

\section{A experiência do uso da música em sala de aula}

Ao trabalhamos música como fonte devemos levar em consideração a maneira em que está sendo proposto em sala de aula, para que para os alunos não fiquem com um conhecimento vago, sem se realizar de fato uma reflexão sobre o que está sendo ensinado, ou seja, uso da música como fonte. Ao pensar a música como fonte histórica devemos considerá-la como um documento histórico, um fragmento de seu tempo, passível de ser explorada pelo historiador. De acordo com Circe Bittencourt (2004) o uso de documentos nas aulas de história justifica-se pelas contribuições que esse pode oferece ao educando:

(...) uma delas é facilitar a compreensão do processo do conhecimento histórico pelo entendimento que os vestígios do passado se encontram em diferentes lugares e fazem parte da memória oficial e precisam ser preservados como patrimônio da sociedade. Outra exigência para o uso das fontes históricas é o cuidado para com as diferentes linguagens. Os documentos como foi anteriormente apresentado, são produzidos sem intenção didática e criados por diferentes linguagens que expressam formas diversas de comunicação. Como recursos didáticos, distinguem-se três tipos de documentos: escritos; materiais ( objetos de arte ou do cotidiano, construções); visuais ou audiovisuais (imagens fixas ou em movimento, gráficas, musicais). (BITTENCOURT, 2004, p. 333)

Com a renovação historiográfica ocorrida no século XX com a Escola dos Analles, esta irá romper com a ideia que documentos históricos eram somente escritos e de cunho oficial, documento passar a ser todo e 
qualquer vestígio deixado pelo homem voluntaria ou involuntariamente (fontes iconográficas, orais, arqueológicas, escritas, música entre outros) cabe ao historiador narrar e dar "dar vida" ao documento, a partir das perguntas que este faz a fonte, sem desprezar a crítica ao documento e a preocupação em conhecer sua origem e o contexto em que foi produzido. "O documento não é qualquer coisa que fica por conta do passado, é um produto da sociedade que o fabricou segundo as relações de forças que aí detinham o poder" (LE GOFF, 1996, p.545).

Mas como podemos trabalhar com documento em sala de aula?

Schmidt e Cainelli falam que o uso do documento em sala de aula parte do pressuposto que o trabalho com as "fontes históricas facilitam a familiarização com as formas de representação do passado e do presente habituando-o a associar conceitos históricos à analise que o origina e fortalecendo sua capacidade em raciocinar sobre a situação dada" os documentos não podem ser "tratados com um fim em si mesmo cabe nesta proposta de ensino professores e alunos estabelecerem um dialogo entre o passado e o presente, tendo como referência o conteúdo a ser ensinado" (SCHMIDT; CAINELLI, 2010, p. 94).

Nesta proposta de acordo com as autoras o processo ensinoaprendizagem está pautado na mediação entre aluno e professor é preciso deixar claro que o uso de documento em sala de aula não pretende transformar o aluno em historiador mais sim motivá-los para o conhecimento histórico, de estimular suas lembranças sobre o passado. 0 uso do documento passou a ser instrumento didático porque ajudaria a tirar o aluno da passividade estabelecendo este contato com as fontes isto suscitaria a discussão deixando as aulas mais agradáveis tanto para alunos quanto para professores.

\begin{abstract}
A presença de outros mediadores culturais, como os objetos da cultura, material, visual ou simbólica, que ancorados nos procedimentos de produção do conhecimento histórico possibilitarão a construção do conhecimento pelos alunos, tornando possível "imaginar", reconstruir o não vivido diretamente, por meio de variadas fontes documentais. (SIMAN, 2004, p. 88).
\end{abstract}


Para Napolitano as músicas têm sido muito utilizadas nas aulas de história, pois aponta para os problemas da sociedade em que seu autor está inserido. Além disso, para ele além da analise da letra da música que é de suma importância, o historiador "nunca deve separar a melodia da letra, pois apesar de a letra ser privilegiada nesses estudos sua melodia, a harmonia, o ritmo da canção influencia e muito na sua compreensão facilitando o entendimento do mesmo" (NAPOLITANO, 2001, p. 08).

Segundo Moraes (2000) a música sempre fez parte da nossa vida, ela atinge a todos, os gostos musicais entre as pessoas são variados, ela segundo o autor pode ser utilizada como fonte para o ensino de diversas disciplinas escolares, no caso da história o autor nos chama a atenção no que tange ao entendimento de determinadas realidades da cultura popular.

Para Perez (2008), mais do que entender a canção como documento, há que se considerar o trabalho com musica também como construção do conhecimento e conceitos levando o aluno a pensar, interpretar, determinado acontecimento histórico entendendo-o como parte de um processo de ensino - aprendizagem, não apenas como algo a ser memorizado.

Para Kátia Abud:

As letras de música se constituem em evidências, registros de acontecimentos a serem compreendidos pelos alunos em sua abrangência mais ampla, ou seja, em sua compreensão cronológica, na elaboração e re-significação de conceitos próprios da disciplina. Mais ainda, a utilização de tais registros colabora na formação dos conceitos espontâneos dos alunos e na aproximação entre eles e os conceitos científicos. Permite que o aluno se aproxime das pessoas que viveram no passado, elaborando a compreensão histórica, que vem da forma como sabemos como é que as pessoas viram as coisas, sabendo o que tentaram fazer, sabendo o que sentiram em relação a determinada situação (ABUD, 2005, p. 316)

Com todas essas questões em mente, preparamos um projeto de aula - oficina para os alunos da $8^{a}$ série ( $9^{\circ}$ ano) do Colégio Estadual Tsuro Oguido. O tema a ser trabalhado seria "A música e a ditadura militar: Como trabalhar com letras de música enquanto documento histórico". Escolhermos estudar as letras das músicas "Metro 743", (1984) "Mosca na 
sopa", (1973) de Raul Seixas "Admirável gado novo" de Zé Ramalho (1979) e "Que país é esse?" Legião Urbana (1987). A maioria dos alunos já conhecia as músicas, mas nunca haviam pensado nelas como um instrumento de estudo para o historiador.

Tomaremos como conceito de aula - oficina o utilizado por Isabel Barca (2004), no qual os alunos são os agentes de sua formação com ideias prévias e experiências diversas, cabendo ao professor ser o investigar social e o organizador de atividade que problematizam o tema que está estudando.

Em um primeiro momento foi realizado um questionário de conhecimentos prévios como objetivo de investigar o que eles entendiam ou sabiam sobre a "Ditadura Militar no Brasil', nossas ideias a cerca de como iríamos trabalhar dependiam do que esses responderiam. Como já estávamos no final do ano (novembro 2011), muitos alunos já se sentiam desmotivados e cansados de irem as aulas, fato que nos preocupou no início, bem como o fato de ser a primeira vez que estaríamos com a turma. Foram apenas três aulas de trabalho, mas já nos ajudou a traçar um perfil da turma e principalmente, situações que poderiam ser melhoradas para as próximas atividades, questões que deveriam ser aprofundadas. Basicamente, entramos na sala de aula com as dicas que a professora regente nos havia passado. Era uma turma tranquila, na medida do possível, não tivemos grandes problemas em trabalha o conteúdo, Os alunos eram participativos e foram receptivos a nossa presença. Conseguimos estabelecer um diálogo com a turma que nos possibilitou trabalhar algumas das questões mais pertinentes a cerca de documento e principalmente, no papel da música enquanto parte constitutiva do contexto histórico de sua as letras não são cópias fiéis do momento histórico ao qual foram escritas.

Levando em consideração a idade e os possíveis gostos musicais, nosso recorte foi a Ditadura Militar, conteúdo que eles já haviam estudado com a professora regente da sala. Para tratar desse tema de uma maneira mais descontraída, e também mostrando aos alunos como trabalhar a música como documento histórico, e o que seria este tal documento; 
levamos três músicas do período da ditadura e uma música do período posterior da Ditadura, todas elas têm uma postura crítica a sociedade em que estão inseridas, a nossa intenção em levá-las foi mostrar o documento como algo palpável aos alunos de como as letras nos ajudam a traçar algumas características da época em que foi escrita.

Já com a turma deste ano (abril de 2012) 90 B tivemos como dificuldade o fato desses alunos ainda não terem tido aula sobre a ditadura militar no Brasil por esse motivo foi necessário intervir com um rápido panorama sobre o que levou o país a ditadura, o que foi propriamente a ditadura, falamos a eles também sobre a repressão no regime militar, tudo isto de maneira geral usando as letras das músicas como tema principal das aulas. Antes mesmo de fazer esse panorama, realizamos um questionário de conhecimentos prévios uma vez que entendemos que os alunos, em algum momento, possam ter ouvido falar sobre o tema e até ter algum tipo de juízo de valor sobre o mesmo e a partir desse material, poderíamos estruturar nossa intervenção. De maneira geral, o que se percebe é que a maioria não sabia ao certo do que se tratava, alguns identificaram sobre a repressão, outros citaram uma novela do SBT, "Amor e Revolução" (2012), como o único lugar onde ouviram sobre o tema. Acreditamos, principalmente a partir dos questionários, que se fez necessário ter o conteúdo para se discutir do que as músicas falavam uma vez que sem esse suporte, nossa intervenção poderia ficar sem sentido para os alunos. A turma de maneira geral é bem participativa e agitada, no entanto, mostrou interesse pelo tema, principalmente nas letras das músicas, de maneira geral esses conseguiram perceber na letra da música uma crítica a sociedade seja ela atual ou não.

\section{Música e a ditadura}

Com o golpe de Estado de 1964, instalou-se no país, um Estado autoritário e ditatorial. A doutrina da Segurança Nacional traduzia as idéias do regime que se iniciava. A doutrina da Segurança Nacional resume-se 
basicamente segundo Germano, (1993) em "um estado permanente de guerra total, entre o mundo livre da civilização ocidental e cristã (capitalista) e o comunismo internacional e ateu". Para Germano (1993) "guerra total" é a Guerra Fria, manter a ordem e se estabelecer de forma definitiva no poder eram os objetivos do governo militar, a tática de governar o país foram os atos institucionais.

Os Atos Institucionais eram decretos do poder executivo e serviam como mecanismos de legitimação e legalização das ações políticas. A medida que os Atos Institucionais avançavam também avançava a severidade do regime, marcado por sua característica despótica, capaz de vetar os direitos que eram garantidos pela constituição brasileira, estabelecendo a opressão militar e policial e também o silêncio dos opositores. Com o ato institucional no 5 de 13 de dezembro de 1968, instaurava-se no país a repressão e a censura aos meios de comunicações, música; movimentos oposicionistas ao regime passaram a ser caçados, inúmeros manifestantes foram perseguidos, muitos foram presos, outros pagaram com sua própria vida por estarem fazendo oposição ao regime

A música foi um desses instrumentos de oposição, Gilberto Gil, Caetano Veloso, Geraldo Vandré, Chico Buarque, Raul Seixas, foram alguns dos vários artistas brasileiros que compuseram suas canções fazendo crítica ao governo e principalmente contra a censura imposta através do AI- 5.

As musicas que trabalhamos com nossos alunos foram músicas de protesto contra o contra a sociedade em que seus autores estavam inseridos, as musicas "Mosca na Sopa" (1973), "Metro linha 743" (1984) ambas de Raul Seixas;" Admirável Gado Novo" (1979), Zé Ramalho; "Que País é Esse" (1987) Legião Urbana.

\section{Metro Linha 743 - Raul Seixas. - 1984}

Raul Seixas quis fazer um disco lamentando a Ditadura e o atraso que ela causou no país, essa música foi lançada no final da ditadura ,toda a letra desta música versa sobre a censura em que os artistas estavam 
sujeitos, no qual o pensar era visto com preocupação, os cidadãos comuns também sofriam com o regime, grandes aglomerações logo eram dispersas, pois representavam grande perigo aos "ideais do Estado".

Ele ia andando pela rua meio apressado

Ele sabia que tava sendo vigiado

Cheguei para ele e disse: Ei amigo, você pode me ceder um cigarro?

Ele disse: Eu dou, mas vá fumar lá pro outro lado

Dois homens fumando juntos pode ser muito arriscado!

Disse: O prato mais caro do melhor banquete é

O que se come cabeça de gente

Que pensa e os canibais de cabeça descobrem aqueles que pensam

Porque quem pensa, pensa melhor parado.

Desculpe minha pressa, fingindo atrasado

Trabalho em cartório mas sou escritor,

Perdi minha pena nem sei qual foi o mês

Metrô linha 743

O homem apressado me deixou e saiu voando

Aí eu me encostei num poste e fiquei fumando

Três outros chegaram com pistolas na mão,

Um gritou: Mão na cabeça malandro, se não quiser levar

chumbo quente nos cornos

Eu disse: Claro, pois não, mas o que é que eu fiz?

Se é documento eu tenho aqui...

Outro disse: Não interessa, pouco importa, fique aí

Eu quero é saber o que você estava pensando

Eu avalio o preço me baseando no nível mental

Que você anda por aí usando

E aí eu Ihe digo o preço que sua cabeça agora está custando

Minha cabeça caída, solta no chão

Eu vi meu corpo sem ela pela primeira e última vez

Metrô linha 743

Jogaram minha cabeça oca no lixo da cozinha

$\mathrm{E}$ eu era agora um cérebro, um cérebro vivo à vinagrete

Meu cérebro logo pensou: que seja, mas nunca fui tiete

Fui posto à mesa com mais dois

E eram três pratos raros, e foi o maitre que pôs

Senti horror ao ser comido com desejo por um senhor alinhado

Meu último pedaço, antes de ser engolido ainda pensou

grilado:

Quem será este desgraçado dono desta zorra toda?

Já tá tudo armado, o jogo dos caçadores canibais

Mas o negócio aqui tá muito bandeira

Dá bandeira demais meu Deus

Cuidado brother, cuidado sábio senhor

É um conselho sério pra vocês

Eu morri e nem sei mesmo qual foi aquele mês

Ah! Metrô linha 743 


\section{Mosca na sopa - Raul Seixas. - 1973}

Mosca na sopa, 1973, foi uma das primeiras músicas da carreira solo de Raul Seixas. A mosca nesta letra, embalado por sons de atabaques e berimbaus, deixa evidente que, já que sempre "há um obstáculo no meio do caminho" Seixas será aquele inseto indesejado que perturba os que estão no poder (militares). A letra mostra o jogo dialético contra os militares que são para ele o verdadeiro obstáculo, Raul Seixas deixa clara a sua insatisfação contra a censura, nos trechos" E não adianta vir me dedetizar [...] Porque você mata uma e vem outra em meu lugar'"[...] Eu to sempre junto de você/ água mole em pedra dura tanto bate até que fura".

Eu sou a mosca

Que pousou em sua sopa

Eu sou a mosca

Que pintou prá Ihe abusar... (3x)

Eu sou a mosca

Que perturba o seu sono

Eu sou a mosca

No seu quarto a zumbizar...(2x)

E não adianta

Vir me detetizar

Pois nem o DDT

Pode assim me exterminar

Porque você mata uma

E vem outra em meu lugar...

Eu sou a mosca

Que pousou em sua sopa

Eu sou a mosca

Que pintou prá Ihe abusar... (2x)

-"Atenção, eu sou a mosca

A grande mosca

A mosca que perturba o seu sono

Eu sou a mosca no seu quarto

A zum-zum-zumbizar

Observando e abusando

Olha do outro lado agora

Eu tô sempre junto de você

Água mole em pedra dura

Tanto bate até que fura 
Quem, quem é?

A mosca, meu irmão!"

Eu sou a mosca

Que posou em sua sopa

Eu sou a mosca

Que pintou prá Ihe abusar... (2x)

E não adianta

Vir me detetizar

Pois nem o DDT

Pode assim me exterminar

Porque você mata uma

E vem outra em meu lugar...

Eu sou a mosca

Que pousou em sua sopa

Eu sou a mosca

Que pintou prá Ihe abusar... (2x)

Eu sou a mosca

Que perturba o seu sono

Eu sou a mosca

No seu quarto a zumbizar..

Mas eu sou a mosca

Que pousou em sua sopa

Eu sou a mosca

Que pintou prá Ihe abusar...

\section{Admirável Gado Novo - Zé Ramalho. - 1979}

Admirável Gado Novo, música de Zé Ramalho faz uma forte crítica social, tendo em vista que o Brasil passava por um dos períodos mais difíceis da sua história, a ditadura militar. Ramalho faz uma metáfora entre o gado e o povo, para ele vivemos em uma sociedade controlada, condicionada a viver em uma ordem estabelecida através do conformismo, fica claro na a letra da música que estamos sempre sendo guiados a caminhos já pré estabelecidos pelos que estão no poder, a ditadura com toda sua estrutura de poder nos faz isto muito bem seja pela força ou pelo seu discurso.

Vocês que fazem parte dessa massa

Que passa nos projetos do futuro,

É duro tanto ter que caminhar

E dar muito mais do que receber, 
E ter que demonstrar sua coragem

À margem do que possa parecer,

$E$ ver que toda essa engrenagem

Já sente a ferrugem lhe comer.

$\hat{E}$, vida de gado...

Povo marcado,

Povo feliz...

Lá fora faz um tempo confortável,

A vigilância cuida do normal;

Os automóveis ouvem a notícia,

Os homens a publicam no jornal,

E correm através da madrugada,

A única velhice que chegou;

Demoram-se na beira da estrada

E passam a contar o que sobrou.

$\hat{E}$, vida de gado...

Povo marcado,

Povo feliz...

O povo foge da ignorância,

Apesar de viver tão perto dela, E sonham com melhores tempos idos, Contemplam essa vida numa cela, E esperam nova possibilidade De verem esse mundo se acabar;

A Arca de Noé, o dirigível

Não voam nem se podem flutuar.

$\hat{E}$, vida de gado...

Povo marcado,

Povo feliz...

\section{Que País é esse? - Legião Urbana - 1987}

Ao compor está música Renato Russo, vocalista da banda Legião Urbana, faz uma canção de protesto mostrando os problemas políticos e sociais que envolvem nosso país, Russo faz um panorama geral sobre os problemas que envolviam o Brasil naquele período, cabe pensar que em 1987 estávamos saindo de uma ditadura militar, na qual enfrentamos perseguições políticas, as mortes de homens e mulheres que lutavam para a redemocratização do país, isto fica claro no trecho "Sangue anda solto Manchando os papéis e documentos fiéis" 
Outra questão que se pode trabalhar em sala de aula com esta música é mostrar aos alunos que a canção escrita em 1987 ainda pode retratar problemas sociais que enfrentamos como a corrupção algo que infelizmente vemos com freqüência nos meios de comunicação.

Nas favelas, no Senado

Sujeira pra todo lado

Ninguém respeita a Constituição

Mas todos acreditam no futuro da nação

Que país é esse?

Que país é esse?

Que país é esse?

No Amazonas, no Araguaia iá, iá,

$\mathrm{Na}$ baixada fluminense

Mato grosso, Minas Gerais e no

Nordeste tudo em paz

Na morte o meu descanso, mas o

Sangue anda solto

Manchando os papeis e documentos fiéis

Ao descanso do patrão

Que país é esse?

Que país é esse?

Que país é esse?

Que país é esse?

Terceiro mundo, se foi

Piada no exterior

Mas o Brasil vai fica rico

Vamos faturar um milhão

Quando vendermos todas as almas

Dos nossos índios num leilão

Que país é esse?

Que país é esse?

Que país é esse?

Que país é esse?

\section{Conhecimentos prévios e avaliação}


Sobre o questionário de conhecimentos prévios e a avaliação, aplicados em sala de aula, o que fica nítido é que muitas vezes os alunos até entenderem o que foi proposto, o que foi visto em sala, a maior dificuldade encontrada é escrever, colocar no papel suas ideias. Eles têm uma enorme dificuldade de transcrever o que sabem, embora quando questionados dentro da sala de aula, participem e demonstrem que entenderam o conteúdo.

Como já fora mencionado, o questionário de conhecimentos prévios fez-se necessário, uma vez que queríamos partir nossas aulas pelo que os alunos já tinham em mente sobre o tema. Responderam o questionário 29 alunos sendo 18 do sexo feminino e 11 do sexo masculino. Em resposta a pergunta sobre o que significava "Ditadura Militar", a grande maioria não sabia explicar do que se tratava ditadura militar e se o Brasil já havia passado por uma. Alguns conseguiam estabelecer que se tratava de um governo militar, mencionaram sobre as torturas, mesmo que superficialmente.

Na questão sobre a repressão, o que mais chamou atenção é que (apesar da maioria ter respondido que não sabia o que significava esse termo) alguns alunos relacionaram repressão à ordem, rigidez (essas respostas partiram mais do sexo masculino). Apenas uma aluna caracterizou como "Injustiça, eu acho".

Quando questionados sobre se já tinham ouvido dos pais, avós, enfim, de alguém, sobre o assunto, a maioria respondeu que não. Alguns alunos disseram que ouviram alguma coisa sobre o assunto, principalmente de seus avós.

Quanto à atividade, foi proposto aos alunos que fizessem uma estrofe que descrevesse sobre como eles viam a sociedade atual, o espaço a qual estavam inseridos. Com essa atividade queríamos perceber se os alunos conseguiram entender a importância do documento para o trabalho do historiador e como ele é usado para o trabalho historiográfico, partindo do princípio que ao trabalhamos com documento estamos levando em conta a época em que foi produzido, ou seja, não é algo inocente, no qual não seja 
empregado algum juízo de valor. Ao produzirem suas próprias estrofes, colocando suas opiniões, os alunos entenderiam melhor quando se diz que um documento não é neutro.

Embora alguns alunos tenham feito realmente uma estrofe, a grande maioria se ateve a descrever o Brasil como corrupto, uma sociedade sem respeito, violenta e que a tendência é sempre piorar. Foi perceptível pela analise das atividades que os alunos apresentam uma visão muito pessimista em relação ao espaço a qual estão inseridos, dentro e fora da escola. A crítica aos políticos também é bem perceptível. Apresentamos algumas das estrofes produzidas pelos alunos ${ }^{2}$.

Selecionamos algumas das narrativas dos alunos que consideramos mais pertinentes com a proposta que lhes fora dada ${ }^{3}$. A visão negativa presente nas três narrativas que aqui transcrevemos, será percebida em quase todas as outras. Nenhum aluno fez uma consideração positiva relativa à sociedade atual:

"Nos dias passados havia muita guerra no Senado. No momento atual só há políticos roubando, muita corrupção.O mundo de hoje só há assassinato, mentiras, ninguém é bom o bastante $(p /)$ serem pessoas de verdade." ( $V$.

Esta fala nos chamou muita atenção, uma vez que se trata de uma violência, da própria maneira como a polícia é vista por esta aluna e não sabemos ao certo se a aluna realmente foi uma testemunha ocular do fato ou apenas escreveu sobre algo que ouviu:

"O mundo que (nóis) vivemos é cheio de mentiras, falsidade, ninguém respeita ninguém, assaltos, assassinatos acontece toda hora e a polícia acha que tem que ficar de 'fora' agem quando quer, esse dias mesmo, mataram um ser humano, jogaram a viatura em cima do homem, que eles acham que roubaram a casa de um policial, fizeram e refém a mulher dele, na boa eu acho que eles deveriam prender o sujeito e (ñ) matar." (G. R. A.)

\footnotetext{
${ }^{2}$ Em nosso trabalho, nomearemos os alunos apenas com as iniciais dos nomes.

${ }^{3}$ Transcrevemos as narrativas dos alunos tal como foram feitas, mesmo com os erros de ortografia e gramática.
} 
A aluna apresenta considerações da sociedade atual e do considera ruim hoje. Foi a única que citou drogas em seu texto:

"A sociedade está muito complicada, cheia de coisas ruins, como (álcool), (farinha), maconha, cigarro, e estão se perdendo no mundo, em (invez) de ir para a igreja rezar." (G. S.)

\section{Considerações finais}

Após essas análises, consideramos que é fundamental o uso de documentos durante as aulas de História. O documento torna a aula mais interativa, há nos alunos um maior interesse. E principalmente, o aproxima do trabalho do historiador.

Com o uso da música, foi possível mostrar aos alunos um olhar sobre a sociedade em que estávamos estudando ("Ditadura Militar 1964-1985"). A partir desse tipo de documento é que possível se traçar um panorama do período que é estudado.

Com as aulas, percebemos que os alunos se sentem mais estimulados a participar e interagir quando se sentem capazes de construir o próprio conhecimento. O professor, enquanto mediador deve estimular seus alunos a pensar, questionar o documento, tornando a aula mais dinâmica do que apenas se o professor expuser um documento e fizer seus próprios questionamentos a cerca do mesmo.

Dessa maneira, entendemos nossa intervenção como positiva, pois tivemos receptividade por parte dos alunos. Eles participaram das aulas, se mostraram interessados, mesmo que minimamente. Apesar disso, percebemos ainda muitas dificuldades por parte dos alunos em entender como se trabalha com um documento e principalmente em tornar escritas as ideias que eles mesmos formam a cerca do assunto. Entendemos que este não é um trabalho apenas para três aulas, mas que deve ser agregada à prática do professor, como mais um instrumento para se trabalhar em sala de aula. 


\section{Referências Bibliográficas:}

ABUD, K. M. Registro e representação do cotidiano: a música popular na aula de História. Caderno Cedes. Campinas, v. 25, n. 67, p. 309-317, set/dez. 2005.

BITTENCOURT, C. Ensino de História: fundamentos e métodos. São Paulo: Cortez, 2004.

FRANCO, M. L. P. B.; NOVAES, G. T. F. Os jovens do Ensino Médio e suas representações sociais. Cadernos de Pesquisa, n. 112, p. 167-183, 2001

FREIRE, P. Ensinar é uma especificidade humana. In: FREIRE, P. Pedagogia da autonomia: saberes necessários à prática educativa. 29 ed. São Paulo: Paz e Terra, 2004, p. 91-146.

NAPOLITANO. M. História e Música. História cultural da música popular brasileira. Belo Horizonte. Ed. Autêntica, 2001.

MORAES, J. G. V. de. História e Música: canção popular e conhecimento histórico. Revista Brasileira de História. São Paulo: Humanitas Produções. v. 20. n.39. 2000.

PEREZ, I. C. G. Estado Novo através da música: uma experiência em sala de aula. Curitiba: SEED- PR, 2008.

SCHMIDT, M. A.; CAINELLI, M. Ensinar história. São Paulo: Scipione, 2004.pag. 111-136

SIMAN, L. M. de C. O papel dos mediadores culturais e da ação mediadora do professor no processo de construção do conhecimento histórico pelos alunos. In: ZARTH, P. A. (Org.). Ensino de História e Educação. Ijuí: Ed. UNIJUÍ: 2004. Pag. 88

\section{Letras Utilizadas:}

SEIXAS, Raul. Metro linha 743. Disponível: http://www.vagalume.com.br/raul-seixas/metro-linha-743.html. Acesso $12 / 10 / 2011$.

SEIXAS, Raul. Mosca na Sopa. Disponível http://www.vagalume.com.br/raul-seixas/mosca-na-sopa.html. Acesso $12 / 10 / 2011$.

RAMALHO, Zé. Admirável Gado Novo. Disponível : http://www.vagalume.com.br/ze-ramalho/admiravel-gado-novo.html. Acesso 18/10/2011. 
RUSSO, Renato. Que país é esse? Disponível.

http://www.vagalume.com.br/legiao-urbana/que-pais-e-esse.html. Acesso $\underline{18 / 10 / 2011 .}$. 